\title{
NOVAS FACES DA VIOLÊNCIA ESCOLAR: POSSÍVEIS DIÁLOGOS ENTRE MORAL E VIOLÊNCIA
}

Rodrigo Cesar Costa, Drielly Adrean Batista, Aline kadooka, Rita Melissa Lepre

Programa de pós-graduação em psicologia da Universidade Estadual Paulista “Júlio de Mesquita Filho" (UNESP-Assis). E-mail: Stanley jordan@hotmail.com

\section{RESUMO}

A violência, fenômeno multifacetado e socialmente recorrente, há muito invadiu os muros das escolas. Diversos são os relatos sobre manifestações de violência na escola que vão desde a violência simbólica, verbal até a física. Sendo assim, este trabalho tem como objetivo compreender as atuais concepções sobre a violência e articular estas com as teorias do desenvolvimento da moralidade humana, com o intuito de estudar as formas de como essa violência, segundo a teoria do desenvolvimento moral, aparece nas escolas na contemporaneidade. Concluímos que as teorias do desenvolvimento moral, tanto na sua parte teórica quanto metodológica, andam se tornando fundamentais na busca de diálogos que promovam mais amadurecimento de conceitos como: a dignidade, a justiça, a bondade, a solidariedade e ao respeito a outros seres humanos, com o intuito de promover uma educação pacificadora e, desta forma, anular significativamente a violência e a sua banalização, principalmente nas escolas.

Palavras-chave: Violência; desenvolvimento moral; escola; contemporaneidade; bulliyng.

\section{INTRODUÇÃO}

A violência é um fenômeno social e psíquico. Sempre esteve presente em todas as épocas, momentos históricos, contextos e classes sociais, sendo expressa de diferentes maneiras. Segundo Fraga (2002), a violência continuamente se encontrou presente na humanidade, confundindo-se com sua própria constituição. Desde as épocas mais remotas, o homem usava ferramentas para se defender das constantes ameaças suscitadas pela natureza e pelos outros humanos, reconhecidos como potenciais agressores.

Para Peralva (2000), a violência cresceu drasticamente no fim dos anos 70 e começo dos anos 80 nas metrópoles brasileiras. Este mesmo autor considera que o grande responsável pelo crescimento da violência foram o aumento da desigualdade social e a injustiça que muitas pessoas sofrem, sendo que a justiça faz grandes promessas, mas, muitas vezes, não cumpre seu papel. Segundo Misse (1999), é fundamental ressaltar que a violência, na atualidade, comporta um vasto campo de significados. Desta forma, não se pode usar essa expressão de forma particular, isto por que não existe somente a violência, singular, mas sim violências, de variadas formas e manifestações, em diferentes graus e de definição. 


\section{OBJETIVO}

Compreender a violência segundo as teorias do desenvolvimento da moralidade humana e estudar as formas de como essa violência aparece nas escolas na atualidade. A psicologia da moralidade é uma área que pretende investigar a constituição da moralidade humana, numa perspectiva estrutural cognitivista.

\section{METODOLOGIA}

A proposta deste trabalho foi fazer um levantamento bibliográfico dos trabalhos mais atuais, dentre eles artigos completos, resumos e livros, em vários sites de pesquisas cientificas que tratam da violência nas escolas na contemporaneidade, aos olhos das teorias que dizem respeito à moralidade humana. Foi realizado um estudo partindo da metodologia do estado da arte. Para Norma Ferreira (2002) os trabalhos de pesquisa nomeados estado da arte são compostos em registros descritivos, e sua grande meta é possibilitar ao pesquisador um vasto campo das pesquisas que foram realizadas em torno de temas específicos que interessam ao sujeito. Este mesmo autor ressalta que os trabalhos de estado da arte também podem servir para destacar as lacunas que ainda existem em determinados estudos, seja se tratando das temáticas que não foram satisfatoriamente exploradas, como também acerca das metodologias e novas tendências epistemológicas.

Desta forma, destacamos que poucos trabalhos que foram levantadas na pesquisa tratam da violência nas escolas segundo a teoria da moralidade, e isto criou possibilidades de uma discussão diferente das demais que foram encontradas. No total foram levantados 40 artigos, resumos expandidos e alguns livros, e somente 18 foram usados neste trabalho. A primeira busca teve como palavra chave a violência, a segunda foi violência nas escolas, e por último, violência e moralidade nas escolas. A princípio foi discutida a violência na atualidade, partindo de artigos e livros que tratam do tema. Em seguida, propomos uma discussão sobre a violência segundo a moralidade e as atuais concepções de violência nas escolas. E para encerrar este trabalho, articulamos a violência segundo a teoria da moralidade com os tipos de violência encontrados nas escolas e brevemente apontamos quais as formas de se superar essa problemática. 


\section{RESULTADOS: A VIOLÊNCIA SEGUNDO A TEORIA DA MORALIDADE HUMANA E AS ATUAIS CONCEPÇÕES SOBRE VIOLÊNCIA NAS ESCOLAS}

Correlacionando a violência com a moralidade, La Taille (2009) nos explica o que é a violência e nos oferece uma definição. Para este autor, a violência pode ser entendida como sendo o uso de força excessiva com a intenção de coibir outra pessoa. Mas ele entende que, mesmo o uso de força para coagir sendo caracterizado como violento, dependendo das circunstâncias, pode ser legitimado. Como exemplo, uma mãe pode obrigar o filho a comer frutas, o ato em si é violento, mas sua finalidade é nutrir seu filho, ou seja, é uma intenção boa por trás do ato que pode ser classificado até como violento. Desta forma, essa atitude é considerada moral.

Para Kolhberg (1992) a moralidade se efetiva por estágios hierárquicos e o centro da moralidade é o principio da justiça, acompanhado de uma formulação racional e estruturalista.

Para este mesmo autor, a primeira etapa é o nível pré-convencional, composto pelos primeiro e segundo estágios. Este nível é baseado em necessidades individuais, tendo como característica o hedonismo e o comportamento egoísta. O segundo nível é o período convencional, baseado no desempenho correto de papeis e no atendimento de expectativas, sendo composto pelos estágios três e quatro. O último nível é o pós-convencional, baseado na moralidade por princípios universalizantes, no qual estão os estágios cinco e seis, que caracterizam os estágios mais desenvolvidos da moralidade.

A respeito do juízo moral, inspirado nesses estudos de Kolhberg, e a violência, Blasi (citado por LA TAILLE, 2009) fez um estudo que procurou corroborar que indivíduos violentos possuem um juízo moral baixo, ou melhor, um juízo que corresponde ao estágio pré-convencional.

Apesar deste estudo de Blasi ser coerente, não se pode generalizar que todas as pessoas violentas possuem um juízo moral inferior. Como exemplo, muitos adolescentes classificados como delinquentes possuem características próprias do estágio convencional, este que é natural da grande parte da população. Partindo desta mesma ideia, Mucchielli (Apud LA TAILLE, 2009) nos diz que os adolescentes que vão se desenvolvendo e, posteriormente, acabam se tornando delinquentes violentos, geralmente possuem um Eu que não obteve valores e normas estabelecidos em sua evolução enquanto sujeito.

Alguns autores não concordam plenamente com essa ideia mencionada anteriormente. Touraine (Apud La Taille, 2009) nos diz que alguns jovens têm incorporado alguns valores culturais, dentre eles se destaca os valores estabelecidos pelo consumismo, desta forma, Touraine 
crê que os indivíduos violentos possuem um tipo de socialização e valores diferenciados, que são paradoxais com os valores que grande parte da população acredita serem corretos.

Partindo dessas ideias situadas acima, conjuntamente com o que as teorias da moralidade definem como violência, procuraremos correlacionar a violência presente nas escolas na atualidade com a psicologia da moralidade. Mas antes de tecer tais considerações, iremos contextualizar a violência nas escolas na contemporaneidade.

Para Levisky (2009), a família é a principal responsável pela socialização do indivíduo, e que logo depois dela aparece à escola. Esta é fundamental para o desenvolvimento do sujeito e pela inserção deste na sociedade como um ser cidadão.

Segundo Abramovay e Rua (2002) a violência que aparece nas escolas pode ser compreendida de três formas. A primeira é a violência direta contra alguma pessoa e/ou algum patrimônio da escola. Em segundo é os desacatos e a violência pela falta de sentido pedagógico, isto se dá pela qualidade ruim do ensino que é proporcionado aos jovens. E por último é em relação à escola se encontrar, muitas vezes, implantada em um espaço violento e nocivo, e por isso, a escola acaba sendo infectada por este mal ambiente.

Para Lopes (2005), o bullying é a forma no qual a violência mais aparece dentro das escolas. Por bullying podemos compreender todas as formas e comportamentos agressivos que frequentemente acontece entre os alunos em todo o ambiente escolar. O mais interessante é que essas atitudes geralmente ocorrem sem algum motivo aparente, e sempre suscita um sofrimento no outro que é agredido.

Smith (2002) aponta que as principais condutas do bullying são as ofensas geradas por apelidos, intimidações, ameaças, injustiças, alguns constrangimentos que são provocados por banalização da vítima, agressões físicas e psíquicas. Geralmente, os alunos que são vitimas do bullying apresentam baixo autoestima e, conforme essas ofensas se tornem constantes, pode provocar um problema sério á longo prazo na vida de quem sofre o bullying.

\section{DISCUSSÃO: ANÁLISE DA VIOLÊNCIA NA ESCOLA POR MEIO DA PSICOLOGIA DA MORALIDADE HUMANA}

É comum observar nas escolas as crianças e adolescentes agressivos, que transgridem as leis e violentam seus amigos de classe. Os mais presentes tipos de violência são os furtos, agressões físicas, pichações na escola, bulling, dentre outros. O que assusta é que essas atitudes ocorrem sem uma causa visível que justifique esses atos. 
Para La Taille (2009) a violência é caracterizada como o abuso do outro, sem uma finalidade que justifique essa atitude. Dessa forma, a violência nas escolas, nas suas mais diversificadas formas, tem como peculiaridade a falta de consideração do agressor ao oprimido pelo ato violento, seja ele direta ou indiretamente. Uma das maneiras mais comuns de violência nas escolas é o denominado bullying, como citado anteriormente nesse trabalho.

O bullying, segundo Constantini (2004), é um termo de origem inglesa, e pode ser entendido como um campo de comportamentos agressivos que tem por finalidade o abuso de poder de um indivíduo sobre a sua vítima. È comum também relacionar o bullying á ameaça física e a violência psicológica. Interessante notar que essa definição de bullying é bem semelhante ao que La Taille (2009) definiu por violência, sendo que ambas é um tipo de comportamento agressivo que tem por finalidade a dominação e o abuso de poder de uma pessoa sobre a outra, sem qualquer justificativa para essa conduta, sem algum motivo aparente.

La Taille (2009) destaca que a moral é uma atitude relacionada á importância dada ao outro ser humano, como o respeito, a compaixão, a justiça, pois este "outro" é um indivíduo que também possui vontades, necessidades, desejos e dignidade. Exemplificando o ato violento, uma das formas mais corriqueiras de violência, do ponto de vista moral, é o comportamento grosseiro que, mesmo não sendo uma agressão física, é classificada como uma atitude violenta, isto pelo simples fato de ser um ato de desrespeito com o próximo. Partindo dessa ideia, é muito frequente nas escolas aparecerem não só as violências físicas, mais fáceis de serem identificadas, mas também, e com grande frequência, este tipo de violência mais indireta, caracterizada pelos xingamentos, desrespeito com o semelhante, atos de grosseria, dentre outros. No ponto de vista moral, qualquer comportamento que tem como finalidade o uso e desrespeito do outro é classificado como violento.

Para La Taille (2009), a violência é um fenômeno bem presente nas salas de aula. È muito comum aparecerem às indisciplinas nas escolas, das suas mais variadas formas, como exemplo, as brigas constantes entre os alunos e dos alunos com os professores. Podem-se compreender estas atitudes pela falta de limites, incivilidade e indisciplina, todas estas remetendo a violência.

Assim, quando existe desrespeito, negação do outro e humilhação sem fins, está presente a violência propriamente dita. Em outras palavras, a violência pode ser entendida como sendo: "um ato que coloca outrem como meio e não como fim. A violência traduz um uso instrumental de outrem, uma negação do seu estatuto de sujeito" (LA TAILLE, 2009, p.332). 
Seguindo essas ideias mencionadas por La Taille, no qual a violência é caracterizada pelo uso do outro, podemos compreender as características dos autores da violência escolar. Segundo Lopes Neto (2005), os principais agentes de comportamentos violentos nas escolas, aonde se sobressai às práticas do bullying, apresentam atributos bem peculiares, dentre eles se destacam: a agressividade, a vontade em dominar o outro, não seguir as regras impostas pela escola, conduta antissocial, temperamental, a procura sempre pela popularidade na escola e a liderança.

\section{CONCLUSÃO}

Segundo Lopes Neto (2005), a violência, nas suas mais variadas formas de se manifestar, vem acontecendo em grande dimensão nas escolas, entretanto, muitos das pessoas envolvidas no campo educacional tem mínimas informações e entendimento acerca da violência e suas implicações para as vítimas, e consequentemente, a precaução dessa violência se torna muito difícil. Dessa forma, para lidar com esse fato, é necessária a criação de ideias que previnam essas condutas e que envolvam o maior numero de pessoas que compõe a escola, dentre eles: pais, professores, funcionários e os próprios alunos.

Para Lourenço (Apud De Souza, 2007), as teorias do desenvolvimento moral, tanto na sua parte teórica quanto metodológica, andam se tornando fundamentais na busca de diálogos que promovam mais amadurecimento de conceitos como: a dignidade, a justiça, a bondade, a solidariedade e ao respeito a outros seres humanos, com o intuito de promover uma educação pacificadora e, desta forma, anular significativamente a violência e a sua banalização, principalmente nas escolas.

\section{REFERÊNCIAS}

ABRAMOVAY, M. \& RUA, M. G. Violências nas escolas. Brasília: UNESCO, 2002.

CONSTANTINI, A. Bullying, como combatê-lo? Prevenir e enfrentar a violência entre jovens. São Paulo: Itália Nova, 2004.

DE SOUZA, L.K. Educação para a paz e educação moral na prevenção à violência. Psic. da Ed., São Paulo, 25, 20 sem. de 2007, pp. 131-155.

FERREIRA, N. S. de A. As pesquisas denominadas "estado da arte". Revista Educação \& Sociedade, Campinas, n. 79, p. 257-272, Ago, 2002.

FRAGA, P. D. Violência: forma de dilaceramento do ser social. Serviço Social \& Sociedade: ano 23, n. 70. p. 44-58, jul. 2002. 
KOHLBERG, L. Psicología del desarrollo moral. Sevilla, Espanha: Editorial Desclée de Brouwer, S.A., 1992.

LA TAILLE, Y. Moralidade e Violência: a questão da legitimação de atos violentos. Temas em psicologia-2009, Vol.17, n.2, p.329-341.

LEVISKY, R.B. Projeto "Abrace Seu Bairro": prevenção da violência no meio escolar e melhoria da qualidade de vida. Revista da SPAGESP - Sociedade de Psicoterapias Analíticas Grupais do Estado de São Paulo Jul.-Dez.2009,Vol.10, No. 2, pp. 41-48.

LOPES NETO, A. A. Bullying - comportamento agressivo entre estudantes. Jornal de Pediatria, v. 81, n. 5, p. 164-172, 2005. http://dx.doi.org/10.1590/S0021-75572005000700006

MISSE, M. Malandros, marginais e vagabundos \& a acumulação social da violência no Rio de Janeiro. Tese (Doutorado em Sociologia) Instituto Universitário de Pesquisas do Rio de Janeiro (luperj), Rio de Janeiro, 1999.

PERALVA, A. Violência e democracia. São Paulo: Paz e Terra, 2000.

SMITH, P. K. Intimidação por colegas e maneiras de evitá-la. In:DEBARBIEUX, É.; BLAYA, C. (Org.). Violência nas escolas e políticas públicas. Brasília: Unesco, 2002. P. 187-205. 